Rev Biomed 2005; 16:281-288.

\title{
La sangre en la historia de la humanidad.
}

\section{Historia de la Medicina}

Renán A. Góngora-Biachi.

Centro de Investigaciones Regionales “Dr. Hideyo Noguchi”, Universidad Autónoma de Yucatán. Sociedad Yucateca de Historia y Filosofía de la Medicina, A.C., Mérida, Yucatán, México.

\section{RESUMEN.}

La sangre ha ocupado un lugar muy especial en la historia de la humanidad. Desde los tiempos remotos se le ha otorgado una vital importancia y un místico concepto. A pesar de ser un tejido de fácil acceso, resistió por muchas centurias a los esfuerzos de los investigadores por descubrir su verdadero significado fisiológico. Muy recientemente -apenas el siglo pasado- empezaron a entenderse los secretos de sus procesos patológicos. La sangre, además, es el tejido que más ha motivado la inventiva literaria, es el más vinculado con procesos religiosos y el que más impacto tiene en el pensamiento popular.

(Rev Biomed 2005; 16:281-288)

Palabras clave: Sangre, sangrías, transfusiones, historia de la Medicina.

\section{SUMMARY.}

The blood in the history of the humanity.

In the history of the humanity, the blood has been in a special place. From the ancient times it has given to the blood vital importance and mystical concept. Instead that the blood is a tissue easy to obtain, during many centuries it was resistant to the researches' attempts for discovering its true physiological significance. Recently -the last century-, the blood secrets of its pathology events began to understand. On the other hand, blood is the biological tissue has promoted more literature inventive, is bond to the religion process and has the biggest impact in the popular thinking.

(Rev Biomed 2005; 16:281-288)

Key words: Blood, blood transfusion, bloodletting, history of Medicine.

\section{LA SANGRE Y EL ORIGEN DE LA VIDA.}

Según el Génesis en el capítulo 2, versículo 7 , Dios formó al hombre del polvo, insufló en sus narices aliento de vida y le otorgó de esta manera el espíritu divino, llamado también espíritu vital o alma. El Génesis, el Levítico, el Deuteronomio y el Talmud babilónico, insisten en la similitud entre el alma y la sangre. El Deuteronomio afirma sin rodeos que la sangre es la vida. Y el Génesis nos dice que la soledad de nuestro padre Adán se resolvió cuando su hermosa compañera -Eva, que lo único feo que tenía era la ausencia de ombligo- fue 


\section{RA Góngora-Biachi.}

elaborada a partir de una costilla. En estos principios del siglo XXI, cuando la clonación es un tema de apogeo, podríamos interpretar que Eva derivó de las células pluripotenciales hematopoyéticas contenidas en la médula ósea de la costilla de Adán. Y por supuesto seguimos afirmando que la sangre es vida.

\section{SANGRE Y ENFERMEDAD.}

En la época de Hipócrates, los griegos habían desarrollado un sistema interpretativo del mecanismo de producción de las enfermedades, basado en la teoría de los cuatro humores orgánicos. Puede reconstruirse claramente el camino que llevó al pensamiento griego a este sistema médico: la idea de que el universo está formado por cuatro elementos básicos (agua, aire, fuego y tierra), cada uno de ellos caracterizado por una cualidad específica (humedad, sequedad, calor, frío); la teoría de los contrarios (con especial hincapié en el número cuatro), que sostenía que entre los elementos opuestos debe conservarse un equilibrio para mantener la armonía de los cosmos y la salud en el microcosmos que es el hombre; los efectos producidos por las estaciones del año, que inicialmente eran tres y no cuatro, sobre el cuerpo y la mente; las secreciones orgánicas, que eran al principio tres (sangre, flema y bilis) y luego se transformaron en cuatro, al diferenciarse entre bilis negra y bilis amarilla. Por último, hacía falta alguna hipótesis general que integrara todos estos conceptos, porque, como dice el premio Nóbel Peter Medawar, "La ciencia, sin el apoyo de las hipótesis, es sólo arte culinario".

El principio básico fue la teoría según la cual todos los fluidos orgánicos están compuestos, en proporción variable, por sangre (caliente y húmeda), flema (fría y húmeda), bilis amarilla (caliente y seca) y bilis negra (fría y seca). Si estos "humores" se encuentran en equilibrio, el cuerpo goza de salud; en cambio, el exceso o defecto de alguno de ellos produce la enfermedad.

Las teorías humorales de los primeros filósofos griegos fueron utilizadas por Galeno (129 a.C.-200 a.C.). Los cuatro humores fundamentales (sangre, flema, bilis amarilla y bilis negra), responsables de la salud y de la enfermedad, le sirvieron de base para clasificar los temperamentos en cuatro tipos: flemáticos, sanguíneos, coléricos y melancólicos. Estos términos se utilizan todavía hoy para designar el carácter de una persona. Galeno ha sido probablemente el autor que más ha influido en el desarrollo de la Medicina. Durante cerca de 15 siglos sus trabajos fueron la autoridad indiscutible.

Pero volvamos a la teoría humoral. Existen tres etapas en toda enfermedad: el cambio en las proporciones humorales causado por factores externos o internos; la reacción del organismo ante esa alteración, manifestada por la fiebre o "ebullición"; la crisis final, en la que la alteración acaba con la eliminación del humor que está en exceso, o con la muerte. Y de la necesidad de la eliminación del humor, derivó el concepto de la sangría.

Hipócrates recomendaba la sangría terapéutica cerca del órgano enfermo para eliminar los humores excesivos localizados ahí (efecto derivativo) y también lejos del órgano enfermo para evitar que continuasen llegando a él dichos humores (efectos revulsivos). La sangría derivativa no debía ser necesariamente copiosa y se acostumbraba practicarla con sanguijuelas o ventosas. La del tipo revulsivo era más abundante y se efectuaba por medio del cuchillo (flebotomía).

Galeno utilizó con frecuencia las sangrías, basándose en la teoría de los cuatro humores, pero fue el primero en advertir acerca de las precauciones que había que considerar en cuanto a la cantidad de sangre extraída (figura 1).

Sin embargo la promoción de las sangrías persistió y desde todos los puntos de vista. Así, en el siglo I de nuestra era, Plinio (23-79) expuso la historia del hipopótamo que, cuando se sentía enfermo, clavaba su rodilla en una punta afilada para producirse una sangría y curarse. Se trata de otro ejemplo de la proyección de las creencias de la propia época a períodos anteriores; en este caso, la idea de que la sangría es un tratamiento médico eficaz. Plinio tenía una postura intelectual voraz e

\section{Revista Biomédica}




\section{La sangre en la historia.}

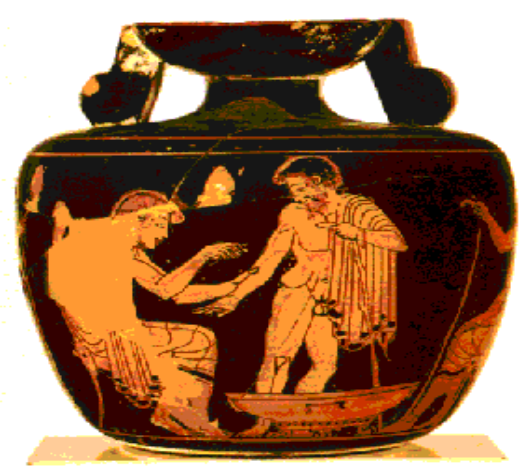

Figura 1.- Frasco de perfume de la época de Hipócrates (primera mitad del Siglo V a.C.) que muestra como un médico cura el brazo de su paciente tras una posible sangría. Le Louvre, París.

indiscriminada. Su monumental Historia Naturalis reúne toda la información que pudo recopilar del pasado y presente. Sin embargo Plinio también tenía una personalidad hemofílica -no por sangrón sino por su afición a la sangre- ya que en su obra describe "lluvias de sangre,...".

Pero las sangrías no fueron únicas del mundo occidental. Era razonable suponer que si la sangre era el alma y por lo tanto la parte más importante de nuestro organismo, debía ser asiento favorito de los espíritus malignos. Y una forma apropiada de echarlos para afuera y hacer sanar al enfermo, era extrayéndole una buena cantidad de sangre. Todas las civilizaciones, desde los tiempos más antiguos, utilizaban la sangría; los babilonios y los egipcios, al igual que los hindúes, los chinos y los aztecas, así como otros amerindios, con frecuencia la practicaban y practican hasta la fecha en algunas regiones (Norte América, Amazonas, Perú). Los mayas precolombinos realizaban sangrías como un mecanismo de "perdón" a los dioses para que estos le restituyeran la salud. Ciertas tribus norteamericanas (los Dakotas, por ejemplo), realizan procedimientos curativos a base de aplicación de ventosas, la sangría, el uso del humo y los baños de vapor. Los hechiceros americanos combinaron tratamientos "mágicos" con medicina "natural", asociando el uso de hierbas, sustancias minerales, productos animales y sangrías, enemas y emplastos, con actos mágico-religiosos del tipo de las danzas rituales y las ofrendas.

\section{SANGRÍAS PROFILÁCTICAS.}

Lógicamente, la sangría no sólo encontró una aplicación terapéutica, sino profiláctica. De acuerdo con la teoría con el animismo, ésta debía efectuarse en forma electiva en días propicios, de acuerdo a los astros, y de ninguna manera cuando la luna y las mareas estaban en su apogeo (días egipciacos). En las mil y una noches se asegura que el mejor momento para la aplicación de la sangría es en el menguante de la luna, con tiempo bueno, de preferencia el 17 del mes y en un martes.

Por eso la sangría encontraba buenos prospectos entre las personas de temperamento sanguíneo, a las que supuestamente les sobraba ese humor (plétora). Las enfermedades febriles y las que causaban dolor, eran en general buenas indicaciones también (figura 2).

\section{EL APOGEO DE LAS SANGRÍAS.}

En el Renacimiento las sangrías fueron utilizadas sin discriminación, sobre todo en las enfermedades infecciosas y de ahí en adelante se mantuvo el criterio de sangrar en forma copiosa cerca del sitio de la enfermedad y aún se estipuló la sangría total para las fiebres, por medio de la aplicación de sanguijuelas en todo el cuerpo (10 a 50 para los casos comunes). Como hasta el siglo XIX no se tuvo una idea precisa de la relación directamente la pérdida de sangre y la disminución del volumen sanguíneo, no era raro que ocurriesen accidentes con el abuso de la sangría, generalmente atribuidos a la misma enfermedad.

Así, no se sabe bien si la viruela hubiese matado por si sola a Louis XV de Francia. Sus médicos (parece que eran seis, auxiliados por cinco cirujanos y tres boticarios) le propusieron tres sangrías, pero el rey aceptó solamente dos porque temía debilitarse demasiado. Y para no violar los preceptos terapéuticos y al mismo tiempo exceder a la petición real, sólo se le practicaron dos, aunque la segunda fue de doble cantidad.

La actividad sangradora de los médicos franceses en la primera mitad del siglo XIX, capitaneados por Broussais, un cirujano militar 


\section{RA Góngora-Biachi.}

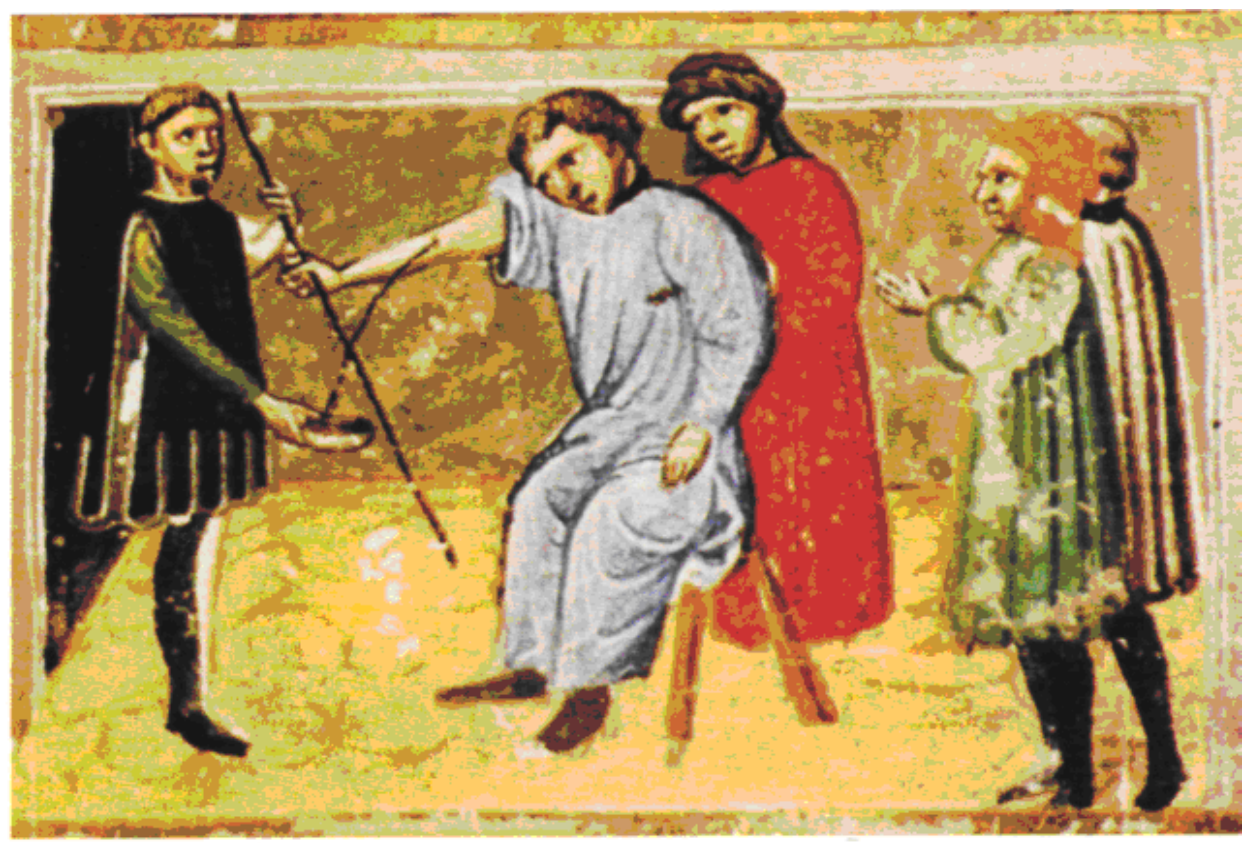

Figura 2.- Práctica de una sangría en un paciente. Ilustración del Canon de la Medicina de Avicena (s. XV).

agresivo, llegó a extremos pocos creíbles. En el año 1830, tuvieron que ser importadas a Francia 41 millones de sanguijuelas, mientras que diez años antes bastaban dos o tres millones para satisfacer todas las demandas.

Las ideas religiosas sobre la menstruación pudieron haber reforzado el fundamento de la sangría. La mujer es impura, y con cada ciclo lunar vierte el exceso de sus impurezas al exterior a través de su matriz El Levítico afirma que en esas circunstancias la mujer permanece contaminada por espacio de siete días; si un hombre se acuesta con ella adquiere su impureza durante siete días también. Si llega a tocar la más pequeña parte de su cuerpo, tendrá que lavar sus vestidos, bañarse en agua y será impuro hasta la tarde.

La medicina árabe llama "mal de amor" a aquel enamoramiento que desborda los límites normales y que, por lo tanto, debe ser tratado por un médico. El libro persa "Los cuatro tratamientos", del médico Aruzi (s. XII), informa en los últimos capítulos sobre el mal de amor. Según este texto, el famoso médico Ibn Sina, curó a un enfermo de esta enfermedad. Observó que al paciente se le aceleraba el pulso al mencionar el nombre de la persona amada, reconociendo así la causa de su mal y prescribiéndole el matrimonio. El príncipe se curó. En la actualidad a veces falla esta receta y en algunos casos el afectado manifiesta que ya no la necesita "porque ya no se le acelera el pulso ni se le para el corazón”.

El médico Alí ibn al-Abbas al-Magusi cita métodos de tratamiento alternativos en su Libro real, donde introduce el "Mal de amor" entre las pesadillas y la parálisis. Contra esta enfermedad recomienda medidas "humedecedoras", como, entre otras, los baños en agua dulce, montar a caballo y mucho deporte. En su opinión también son útiles las fricciones con aceite de clavel, beber vino, contemplar jardines y campos, escuchar bellas melodías, tocar el laúd y cantar salmos. El enfermo debe mantenerse ocupado para que sus pensamientos se desvíen de la persona amada. Debe discutir mucho porque, si así lo hace, con el tiempo olvidará a la persona que con tanta pasión ama. Además, el coito con una persona que no sea la amada ayuda a reducir la pasión y a mantenerse alejados. En caso de no funcionar las recetas anteriores, una sangría doble seguramente era infalible. Yo estoy seguro que la mayoría de los

\section{Revista Biomédica}


pacientes apreciaban más la primera prescripción.

La introducción del análisis numérico (es decir la estadística) y su aplicación a los resultados obtenidos con la sangría, por parte de PierreCharles-Alexandre Louis (1787-1872), produjo no sólo un duro golpe para este procedimiento sino también un reforzamiento de la tendencia incipiente a valorar de forma científica los resultados de los demás métodos terapéuticos. Sin embargo los procedimientos de sangría -aunque muy escasosaún existen en la medicina tradicional y también en la medicina alopática y a través de sanguijuelas.

\section{LA SANGRE COMO FUENTE DE VIDA Y ELEMENTO TERAPEÚTICO.}

Históricamente hablando, y considerando el concepto que el ingreso de sangre a nuestro organismo es vida, el antecedente de la transfusión sanguínea fue la ingesta de sangre.

Plinio el viejo, relata que el circo romano, alrededor del año 100 de nuestra era, la gente se lanzaba a la arena a beber la sangre de los gladiadores moribundos y adquirir así su fuerza y su valor. Entre grupos étnicos de Asia y Meseoamérica de hace 2,000 años, es frecuente encontrar la descripción de la ingesta de sangre humana de los enemigos y también de algunos animales para adquirir fortaleza y, en su caso, las buenas cualidades de los animales. Esta costumbre de ingerir sangre de animales, hasta hace unos pocos años -y quizá hasta estas fechas del año 2005- era practicada en el rastro de la ciudad de Mérida, Yucatán y en las corridas de toros de las poblaciones del interior de este estado mexicano. Por supuesto una manera más sutil de ingerir sangre es a través de un buen taco de "morcilla" (sangre cocida y condimentada, alimento popular en México y algunos países latinoamericanos).

Aunque Willians Harvey hizo su famosa demostración experimental de la circulación sanguínea, aún así, en sus días nadie sabía para que servia exactamente la respiración. El mismo Harvey opinó que era un asunto peliagudo y lo dejó por la paz, admitiendo de mala gana la vieja teoría de
Galeno de que el objeto de la respiración era refrigerar la sangre y enfriara al "fiero" corazón.

En el siglo XVII se inició la práctica de inyectar sustancias en el interior del torrente sanguíneo. Era uso frecuente instilar vino en los perros de caza para el tratamiento de algunas enfermedades. Johann Sigismund Elsholtz (16231688), médico de cabecera de Federico Guillermo de Bradeburgo, en 1665 publica Clysmatica nova, que contiene la primera referencia de una inyección intravenosa en un ser humano (figura 3 y 4). Daniel Major, de Papua (1634-1693), administró medicación intravenosa mediante finos cilindros de plata. Sugirió, cómo habían hecho otros autores, que era posible inyectar sangre en las venas, pero no hay pruebas de que lo realizará en hombres.

Richard Lower (1631-1691) fue el primero en realizar una transfusión directa de sangre, demostrando que la diferencia de color entre la sangre arterial y venosa se debía al contacto con el aire en los pulmones. John Mayow (1640-1679) afirmó que el enrojecimiento de la sangre venosa se debía a la extracción de alguna sustancia del aire. Llegó a la conclusión de que el proceso respiratorio no era más que un intercambio de gases entre el aire y la sangre; éste cedía el espíritu nitro aéreo y cogía los vapores producidos por la sangre.

Richard Lower, en el siglo XVII, fue quizá el primero en realizar una transfusión mediante tubos

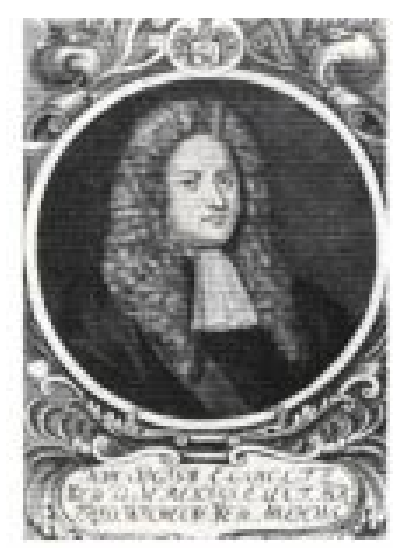

Figura 3.- Johann Sigismund Elsholtz (1623-1688), a quien se le atribuye la aplicación de la primera inyección intravenosa.

Vol. 16/No. 4/Octubre-Diciembre, 2005 


\section{RA Góngora-Biachi.}

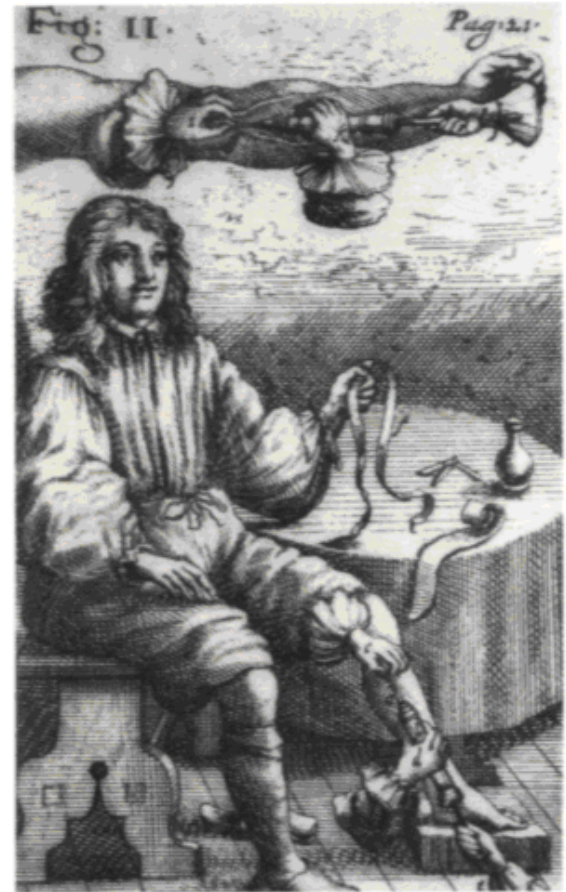

Figura 4.- Primera representación de una inyección intravenosa o infusión en seres humanos. (Joham Sigismund Elsholtz, 1667). de un animal a otro, y, según Samuel Pepys, administró sangre de oveja a un joven con la intención de cambiar su carácter. Se desconocen los resultados de este experimento. Otro investigador de este siglo XVII. Bartholinius, seguramente poco serio, informó el caso de una señorita epiléptica que recibió una transfusión de sangre de gato y luego, en las noches subía al tejado a maullar.

Se considera a Jean-Baptiste Denis como el primero en acometer con éxito una transfusión humana. En 1667 administró tres pintas de sangre de carnero a una persona, sin efectos nocivos aparentes, pero después intento dar sangre de ternera a un muchacho de vida agitada con el fin de suavizar su carácter violento y le produjo una grave reacción que desembocó en la muerte. En el juicio que siguió a este hecho, Denis fue exonerado de toda culpa, pero la facultad de París prohibió futuras transfusiones. Diez años más tarde, el parlamento las declaró ilegales. El gobierno italiano también

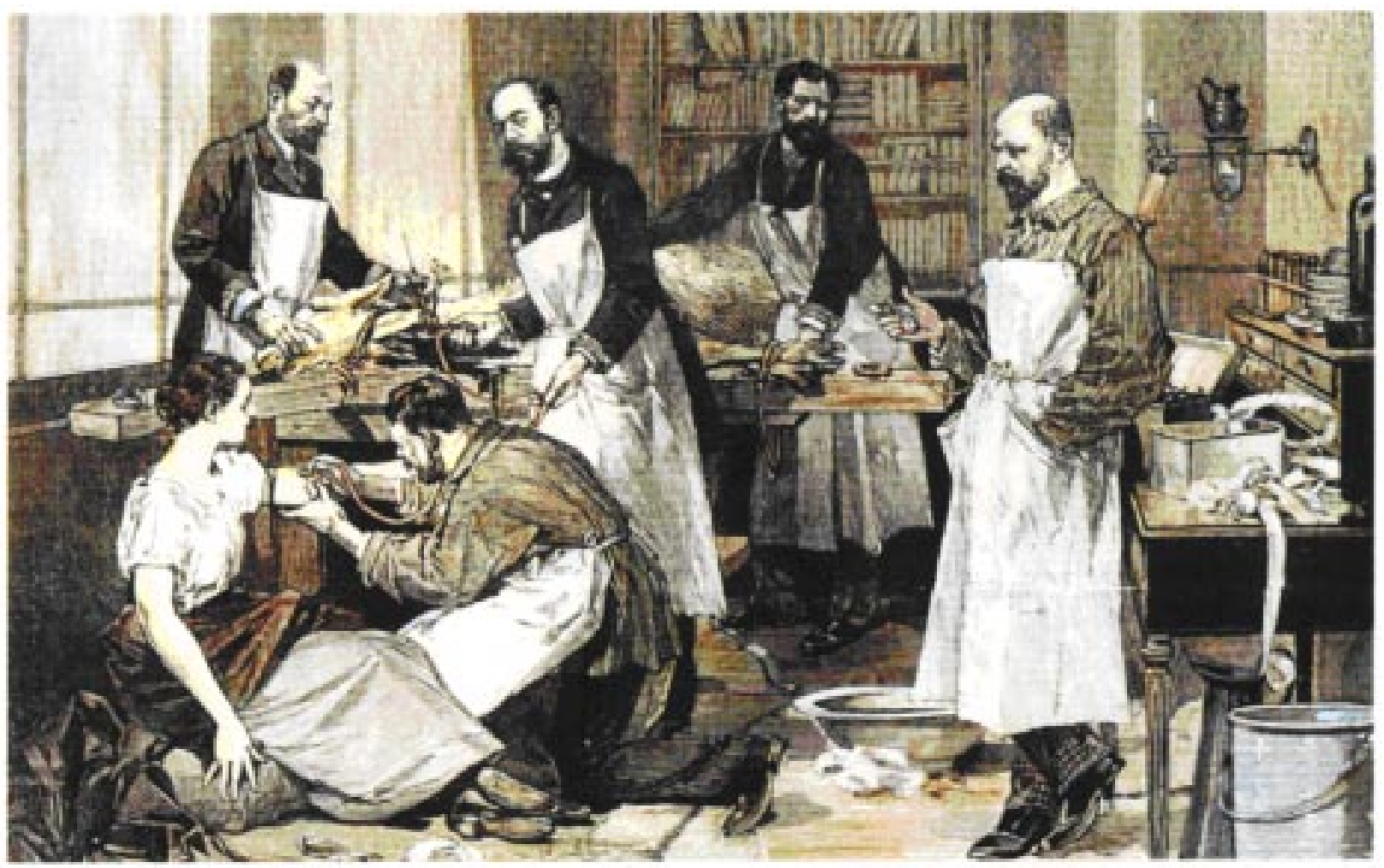

Figura 5.- Intento de curación de un enfermo de tuberculosis con transfusión de sangre de cabra (grabado de 1891, Biblioteca de las Artes Decorativas, París). 
declaró fuera de la ley las transfusiones de persona a persona, pero no así la Real Sociedad de Londres, que mantuvo su conformidad.

Durante los siglos XVII y XIX se demostró, mediante transfusiones experimentales en animales e incluso en hombres, que podía restituirse la sangre de animales desangrados, que la sangre transportaba el oxígeno y que, si se hacía incoagulable mediante extracción de su contenido de fibrina, podía administrarse a animales. Finalmente quedó demostrado que las transfusiones de animales al hombre eran muy peligrosas, pero poco a poco se iniciaron las transfusiones de hombre a hombre (figura 5). Blundell, Ponfick, Landis, Arthur y Pager expusieron los efectos fisiológicos y químicos de las transfusiones, pero fueron los trabajos inmunológicos de Ehrlich, Bordet y Gengou, entre otros, los que permitieron a Karl Landsteiner (figura 6) clarificar la existencia de los grupos sanguíneos, lo que supuso la incorporación sin ningún riesgo de la transfusión sanguínea a la práctica médica.

En 1910 Landsteiner describió los tipos A, B, y O de los hematíes, y posteriormente al tipo $\mathrm{AB}$ y así, la medicina transfusional inició su verdadera etapa científica.

\section{DEL MISTICISMO A LA EXPLICACIÓN CIENTÍFICA.}

Todos los misterios de la sangre empezaron a aclararse en el mismo siglo XVII. Swammerdam y Antonym van Leeuwenhock describieron los glóbulos rojos (figuras 7 y 8) y Malpighi las anastomosis capilares. Boyle y Hooke iniciaron la investigación del oxígeno y Priestley y Lavoiisier la completaron durante el XVIII. Y cuando en el siglo XIX Funke describió la hemoglobina, Paul Erlich clasificó los leucocitos -y estableció claramente a la medula ósea como el órgano hematopoyético- y Alfred Donné y William Addison descubren las plaquetas, como señaló el Dr. Álvaro Gómez Leal, distinguido hematólogo mexicano, "entonces la sangre quedó en el triste papel de un líquido sin significación divina o espiritual".

Sin embargo la sangre también ha acompañado

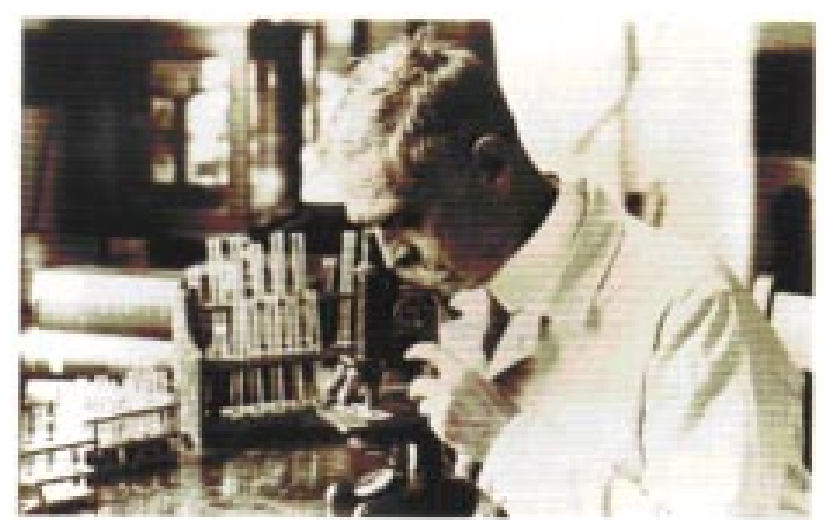

Figura 6.- Karl Landsteiner (1868-1943) descubridor de los sistemas de los grupos sanguíneos.

a la humanidad a través de su historia en la pintura, literatura, música entre otras bellas artes. Un ejemplo de la literatura reciente, en donde le otorgan un primer lugar protagónico a la sangre, referido por el Dr. Gómez Leal, es el relato de García Márquez en "Cien Años de Soledad". Cuando José Arcadio Buendía se suicidó de un pistoletazo, un hilo de sangre, que le botaba del oído derecho, salió por debajo de la puerta, alcanzó la calle, dobló una esquina a la derecha y otra a la izquierda, llegó a la casa de su madre, pasó por la sala pegado a las

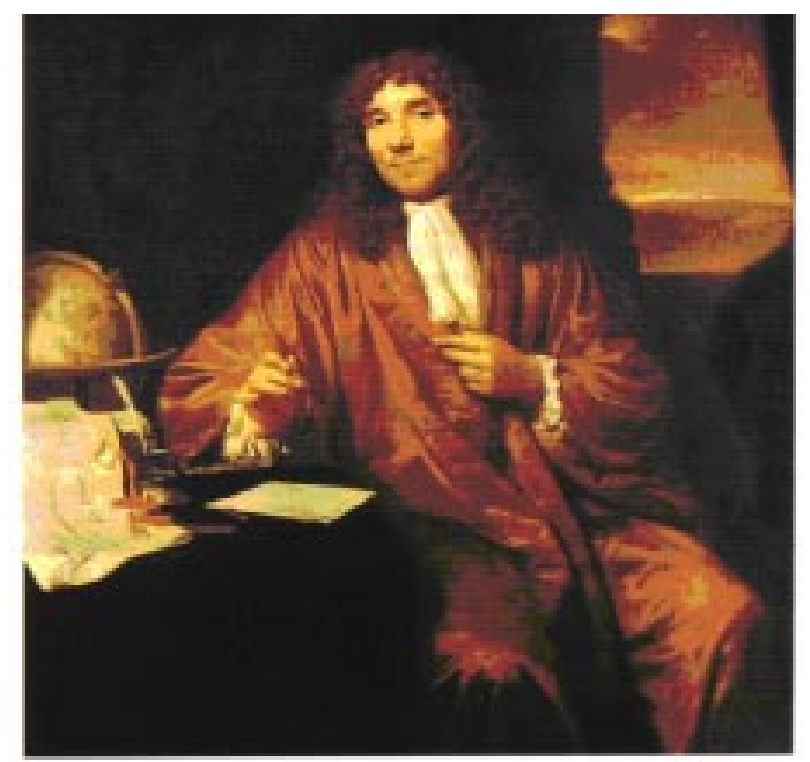

Figura 7.- Antonym van Leeuwenhock (1632-1723), primera persona en describir los corpúsculos sanguíneos a través de un microscopio que el mismo fabricó. Su profesión era la de comerciante de lino, del Delf, Holanda, aunque fue un naturalista experto de su época. 


\section{RA Góngora-Biachi.}

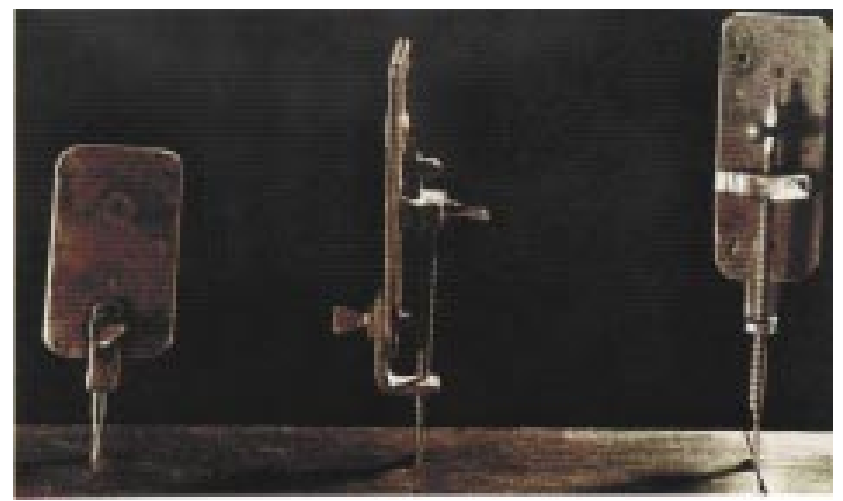

Figura 8.- Microscopio de Antonie van Leeuwenhoek, con la que demuestra la existencia de los glóbulos rojos. (1673).

paredes para no manchar los tapices y apareció en la cocina, donde Úrsula se disponía a partir treinta y seis huevos para el pan. Úrsula exclamó “¡Ave María Purísima!", y siguiendo el hilo de sangre en sentido contrario, encontró el cadáver de su hijo.

Los cultos religiosos, muy especialmente el cristianismo, han considerado a la sangre y algunas veces a sus enfermedades como un elemento importante en su marco teogónico. La estigmatización -o como le llamamos los hematólogos, la Púrpura Psicógena- ha existido a partir de la crucifixión de Cristo. Un ejemplo de quien ha padecido esta enfermedad es San Francisco de Asís, el primer santo ecologista y que promovió la Hematología -a través de sus estigmatizaciones- y por supuesto a la sangre. Yo me he puesto a pensar que si los odontólogos tienen a su patrona que es Santa Apolonia, que como parte de su martirio le extrajeron las piezas dentarias con tenazas, ¿no es San Francisco de Asís un buen candidato para ser patrono de los Hematólogos?

Para finalizar, un comentario. En el 2002, tres comunicaciones científicas fueron altamente favorables para la Sangre. En seres humanos se ha demostrado la existencia de una célula sanguínea capaz de regenerar el hígado y el músculo del corazón. O sea, se transformó en células del hígado y del músculo cardiaco. En primates esta misma célula pudo transformarse en neuronas. En 2005 estos hechos han sido corroborados y se ha acuñado el término de "transdiferenciación" para definirlos. Estas evidencias del mundo moderno apoyan el porqué la sangre es el origen de la vida y el porqué Dios hizo su más grande creación universal -la mujer- de las células tronco pluripotenciales de la médula ósea de la costilla de Adán.

\section{BIBLIOGRAFIA.}

Gómez-Leal A. Evolución del concepto de la sangre a través de la historia. Rev Biomed 1994; 5:161-9.

Izaguirre-Ávila R. El descubrimiento de las plaquetas. Rev Biomed 1997; 8:197-208.

Lavielle P, Martínez-Murillo C. Las enfermedades hemorrágicas y su tratamiento en la Medicina Náhuatl. Rev Biomed 1996; 7:121-4.

Lyons AS, Petrucelli RJ. Historia de la Medicina. Madrid: Ediciones Harcourt. S.A.; 1994.

Martínez-Andrade MA. Mitos de la transfusión sanguínea. Rev Biomed 1993; 4:219-25.

Mez-Mangold L. A history of drugs. Basle: Editions Roche; 1989.

Schott H, Muller IW, Rocicke V, Wolf-Braun B, Schadewaldt H. Crónica de la Medicina. México: Intersistemas, S.A. de C.V. ; 2003.

Urzáis-Jiménez C. Los recursos terapéuticos empleados en la medicina antigua de Yucatán. Rev Biomed 2002; 13:59-68.

Verfaillie C. Stem cell plasticity. Hematology 2005; 10 (supl. 1):293-6.

\section{Revista Biomédica}

